\title{
Influence of Surface Crystalline Structures on DSC Analysis of PTFE
}

\author{
Vinicius Fiocco Sciuti ${ }^{a *}$, Caiuã Caldeira Melo ${ }^{a}$, Leonardo Bresciani Canto ${ }^{a}$, Rodrigo Bresciani Canto ${ }^{a}$
}

\author{
${ }^{a}$ Departamento de Engenharia de Materiais, Programa de Pós-Graduação em Ciência e Engenharia de \\ Materiais - PPGCEM, Universidade Federal de São Carlos - UFSCar, São Carlos, SP, Brasil
}

Received: March 28, 2017; Revised: June 21, 2017; Accepted: July 03, 2017

\begin{abstract}
The physical and mechanical properties of polytetrafluorethylene (PTFE) are greatly dependent on the degree of crystallinity and this is extremely important for the modeling of PTFE processing which is complex and costly. Differential scanning calorimetry (DSC) is one of the most important techniques for the determination of the degree of crystallinity and powder granules of the sample are generally used in the analysis. This procedure provides samples with a high surface-to-volume ratio, resulting in the formation of a considerable number of surface crystalline structures, called warts, along with the bulk crystallization, as shown by scanning electron microscopy. The presence of warts has a significant effect on the PTFE melting enthalpy and thus hinders the correct estimation of the degree of crystallinity of industrial PTFE parts, in which bulk crystallization prevails. In this study, we propose a procedure which does not lead to the formation of warts in the DSC sample and thus allows a more accurate determination of the melting enthalpy (or the degree of crystallinity) of industrial PTFE parts. We demonstrate that samples must be extracted from the core of dense (well-pressed) parts previously sintered in an oven, and the use of powder granules and/or sintering in DSC is not recommended.
\end{abstract}

Keywords: PTFE, DSC, degree of crystallinity, surface crystallization, warts.

\section{Introduction}

Components and parts made of polytetrafluorethylene (PTFE) are expensive due to the high cost associated with this polymer and its processing. Because of its high melt viscosity $\left(10^{9}\right.$ to $10^{11} \mathrm{~Pa} \mathrm{~s}^{-1}$ at $\left.360^{\circ} \mathrm{C}^{1}\right)$, PTFE parts are not manufactured via the traditional melt processing routes for thermoplastic polymers. Instead, PTFE powder granules are cold pressed followed by hot sintering ${ }^{1-5}$. Sintering is usually carried out at temperatures up to $375^{\circ} \mathrm{C}$ (i.e., above the PTFE melting temperature) for between 10 and 10,000 min depending on the size of the specimen, followed by cooling at slow rates, typically in the range of 0.1 to $0.8^{\circ} \mathrm{C}$ $\mathrm{min}^{-1}$, to avoid the formation of microcracks in the specimen. As-received PTFE has a high melting temperature $\left(\mathrm{T}_{\mathrm{m}}\right)$ of around $342{ }^{\circ} \mathrm{C}$ and high degree of crystallinity, in the range of 89 to $98 \%{ }^{2,3}$. After sintering, $\mathrm{T}_{\mathrm{m}}$ is reduced to $\approx 327{ }^{\circ} \mathrm{C}$ and the degree of crystallinity decreases to values between 38 and $53 \%$ depending on the conditions ${ }^{6}$. This is attributed to the high degree of conformational constraint of the PTFE chain during cooling from the melt, which hinders the crystallization ${ }^{7}$.

The outstanding properties of this polymer allow PTFE parts to be used under critical service conditions. In the automotive industry, bearings and bushings made of PTFE are used without additional lubrication because of the good mechanical properties of the polymer along with its low friction coefficient when in contact with a range of surfaces ${ }^{8}$. The high electrical resistivity and thermal

\footnotetext{
*e-mail: vinicius@ppgcem.ufscar.br
}

stability of PTFE make it suitable for use in electrical wire and cable insulations ${ }^{2}$. In the chemical industry, gaskets, vessels, valves and pipes are made of PTFE because of its chemical inertness and high thermal stability, among other properties. All of these PTFE properties are significantly affected by the degree of crystallinity after sintering ${ }^{6,9,10}$. The performance of PTFE specimens in mechanical testing is also influenced by the degree of crystallinity ${ }^{6,9-12}$. Rae and Dattelbaum $^{9}$, for instance, observed an increase of $18 \%$ in the yield stress of PTFE in compression tests with an increase in the degree of crystallinity from 32 to $48 \%$. The tensile behavior of PTFE has also been found to be affected by the degree of crystallinity ${ }^{6}$. Samples with a low degree of crystallinity present higher stiffness and larger deformations than those with a high degree of crystallinity. In the early stages of tensile loading, the PTFE chains in the amorphous phase align in the tensile loading direction. After reaching a certain amount of deformation, the PTFE crystals can slide, stretch and orientate in the direction of the tensile axis $^{6}$. With regard to the fracture behavior, PTFE undergoes localized plastic deformation in the vicinity of microvoids above $19^{\circ} \mathrm{C}$, leading to the formation of fibrils, which results in the dissipation of energy ${ }^{11}$. An increase in the degree of crystallinity of PTFE reduces the fibrillation, thus decreasing the fracture toughness of the material ${ }^{13}$. In this regard, the crack surface displacement mode plays an important role, that is, the formation of fibrils is more pronounced in mode-I than mode-II (shear) ${ }^{14}$. The creep behavior of PTFE are also affected by the degree of crystallinity ${ }^{15}$, along with the 
coefficient of thermal expansion ${ }^{3}$. All of the above-mentioned properties are relevant for the design of PTFE components and parts, which emphasizes the importance of the accurate estimation of the crystallinity degree of PTFE as a function of the heat cycle imposed during sintering. The fact that PTFE processing is complex and costly, along with the significant dependence of the mechanical properties on the degree of crystallinity, has motivated researchers to carry out studies on the characterization and computational modeling of cold pressing $^{16,17}$ and sintering ${ }^{3,18,19}$.

In several studies reported in the literature differential scanning calorimetry (DSC) was used to investigate the melting $^{3-5,7,16,20-23}$ and crystallization ${ }^{3-5,15,16,19-26}$ of PTFE.

Lau and co-workers ${ }^{24}$ used DSC to measure the heat capacity and phase-change enthalpies of two sets of PTFE samples with different degrees of crystallinity in the temperature interval of $-103{ }^{\circ} \mathrm{C}$ to $427^{\circ} \mathrm{C}$. The authors do not mention any processing involving pressing or sintering before the analysis, suggesting that as-received powder granules were used. The as-received samples were considered to be $100 \%$ crystalline and a less crystalline sample was obtained through heat treatment at $352^{\circ} \mathrm{C}$ for $15 \mathrm{~min}$ followed by cooling at $43{ }^{\circ} \mathrm{C} \mathrm{min}^{-1}$ prior to the analysis. The authors suggested that the data reported could be used to update and expand the information on the thermodynamic properties of PTFE available in the literature.

Mantuano and Gomes ${ }^{5}$ studied the effects of cold pressing and sintering time on the microstructure of PTFE parts. They obtained cylinder-shaped specimens by isostatic pressing and disc-shaped samples were extracted from these cylinders. To simulate the sintering, the discs were heattreated by DSC at temperatures between 365 and $380^{\circ} \mathrm{C}$ for time intervals of 5 to $60 \mathrm{~min}$. Thereafter, the crystallization enthalpy was measured by DSC to estimate the dependence of the degree of crystallinity on these sintering conditions. The degree of crystallinity of PTFE was found to decrease with an increase in the sintering time. However, this trend could not be explained by the authors.

Canto and co-workers ${ }^{3}$ subjected PTFE powder granules to a nonstandard cyclic DSC test consisting of successive heating and cooling cycles at between 240 and $360^{\circ} \mathrm{C}$ with different cooling rates. The degree of crystallinity of PTFE was estimated from the ratio between the enthalpies of crystallization and subsequent melting. This strategy allowed the degree of crystallinity to be estimated as a logarithmic function of the cooling rate from a single sample. A slight nonlinearity was obtained but the authors did not address this and applied a linear fitting.

Strabelli and co-workers ${ }^{4}$ investigated the influence of sintering variables on the microstructure and degree of crystallinity of isostatically cold-pressed PTFE parts. Sintering was carried out in an air-circulating oven at three different temperatures $\left(360,375,390^{\circ} \mathrm{C}\right)$ for times ranging from 10 to $10,000 \mathrm{~min}$. The degree of crystallinity was estimated by density measurements and DSC using samples taken from the core of the parts. Data obtained from these two techniques showed good agreement. For these time intervals, the degree of crystallinity was found to increase during the sintering for samples heat-treated at 360 and $375^{\circ} \mathrm{C}$, while the sample sintered at $390^{\circ} \mathrm{C}$ showed a maximum at $1,000 \mathrm{~min}$.

Ganguly and Lesser ${ }^{23}$ investigated the crystallization of PTFE subjected to cyclic thermal loading and isothermal treatment by DSC. Samples were cold pressed in two steps until reaching $2.15 \mathrm{~g} \mathrm{~cm}^{-3}$. Sintering was performed by DSC applying a relatively long time interval (up to 2,000 $\mathrm{min}$ ). It was found that the melting enthalpy of the PTFE samples increased with sintering time. Moreover, the melting enthalpies of the samples subjected to cyclic thermal loading were equivalent to those of the samples subjected to an isothermal condition, for the same sintering time.

Glaris and co-workers ${ }^{25}$, using scanning electron microscopy (SEM), observed the presence of aspherical structures, referred to as warts, on the external surface of PTFE samples subjected to heat treatment in an oven. The heat treatment was replicated in a DSC instrument and the melting enthalpy was measured. The degree of crystallinity was estimated from the ratio between the enthalpies of two subsequent melting events. The authors found that an increase in the degree of crystallinity was associated with an increase in the formation of warts, suggesting that these structures are highly crystalline. Moreover, the number of warts formed and their size were dependent on the thermal history of the samples. The authors concluded that the warts are formed by stress relaxation as a result of the very low surface energy of PTFE.

Gamboni and co-workers ${ }^{26}$ showed that the warts are formed on free surfaces of the PTFE samples, whether external or internal, in the latter case arising from the presence of microvoids inside sintered parts that were not fully dense during isostatically cold pressing. In fact, warts have not been observed in fully dense sintered PTFE parts obtained by multiple-step cold isostatic pressing. Furthermore, the observations of Ganguly and Lesser ${ }^{23}$, that is, that the melting enthalpy of PTFE samples increases with the sintering time applied in the DSC, could be attributed to the formation of warts on the free surfaces of the samples.

In this study, we found that the typical routine for the DSC analysis of PTFE samples in the form of powder granules may not be appropriate for the determination of the degree of crystallization and cannot be used to simulate the sintering of industrial parts, since the measurement is greatly influenced by the formation of the surface crystalline structures known as warts. In addition, it was observed that the bulk and surface (due to warts) crystallization of PTFE cannot be distinguished in DSC analysis. We report herein the use of DSC along with SEM to analyze the formation of warts and their influence on the PTFE enthalpy of melting. We propose a specific DSC procedure, including the sample 
preparation and analytical conditions, to determine accurately the degree of crystallinity of industrial PTFE parts.

\section{Experimental}

\subsection{Material}

The PTFE used is a commercial grade Teflon ${ }^{\circledR} 807-\mathrm{N}$ supplied by DuPont ${ }^{\mathrm{TM}}$. This grade is presently commercialized by Chemours ${ }^{\mathrm{TM}}$ under the code Teflon ${ }^{\mathrm{TM}} 807 \mathrm{~N}$ X. This resin is pelletized after polymerization to form free flowing rounded aggregates called powder granules, with an average size of $\approx 600 \mu \mathrm{m}$ and degree of crystallinity of $\approx 90 \%{ }^{3}$. The freeflowing powder has a porosity of $\approx 60 \%$.

\subsection{Experimental approach}

Surface crystalline structures called warts are formed during heat treatment on the free surfaces of PTFE parts, both external ${ }^{25}$ and internal in the case of poorly compacted parts ${ }^{26}$. Such conditions are frequently found in the DSC analysis of PTFE powder granules, but not in dense industrial parts sintered in an oven. Thus, we assumed that the simulation of the sintering (including the subsequent crystallization) of PTFE by DSC using powder granules may not accurately represent the processing of technical PTFE parts, since it takes into account the surface crystallization as well as the bulk crystallization, the latter being the most relevant in terms of the properties of industrial PTFE parts. To verify our assumption, we compared the responses of two types of specially designed PTFE samples in DSC analysis.

One set of samples was taken from the core of specimens which had been cold pressed (CP) and then sintered. Cold pressing was performed under isostatic loading in multiplesteps ${ }^{26}$ to produce specimens in the shape of bars, as described in section 2.3. These bars were sintered (and then cooled) in an oven using a standard temperature program for PTFE, as described in section 2.4. They were then cut into small pieces with a size similar to that of powder granules $(\approx 600$ $\mu \mathrm{m})$ and placed in DSC pans.

The other set of samples was comprised of as-received (non-pressed but heat-treated, referred to herein as sintered) powder granules (PG). To ensure that the powder granules were thermally treated in a similar manner to the bars, the PG were placed in DSC pans, inserted into a specially designed sample holder made of PTFE (to provide similar conditions of heat exchange; see Figure 1) and then sintered using the same temperature program.

All samples were analyzed by DSC to investigate the effect of the formation of warts on the overall crystallization. Additionally, some selected samples were examined by SEM before and after the DSC analysis to assess the formation of warts. The procedure is shown schematically in Figures 1a-b.

\subsection{Cold Pressing}

Bars with dimensions of $20 \times 10 \times 75 \mathrm{~mm}^{3}$ were isostatically cold pressed in three steps with maximum pressures of 2 , 10 and $35 \mathrm{MPa}$, respectively, which allowed the gradual extraction of the air trapped in the particles and interstices, resulting in a dense part with very low porosity $(\approx 1.4 \%)^{26}$.

\subsection{Sintering}

Samples in the form of powder granules (PG) and cold pressed (CP) bars were sintered in a specially designed home-made tubular oven (shown schematically in Figure 2a). The oven contains an electrical resistor coupled to a PID controller and an air circulating device positioned at the bottom of the tube, which allowed a homogeneous distribution of the inside temperature, with a maximum discrepancy of $\pm 1^{\circ} \mathrm{C}$. The temperature program used for the sintering is shown in Figure 2b. Samples were heated up to $390{ }^{\circ} \mathrm{C}$ and held at this temperature for time intervals ranging from $\Delta \mathrm{t}=120$ to $8,000 \mathrm{~min}$ and then cooled to 40 ${ }^{\circ} \mathrm{C}$ at $0.3{ }^{\circ} \mathrm{C} \mathrm{mim}^{-1}{ }^{16}$.

\subsection{Differential Scanning Calorimetry - DSC}

DSC experiments were performed using a TA Instruments calorimeter (model Q2000) with hermetic aluminum pans under nitrogen atmosphere $\left(50 \mathrm{~mL} \mathrm{~min}^{-1}\right)$. Three replicate samples $(7.5 \pm 0.1 \mathrm{mg})$ were analyzed for each sintering condition. The calorimeter was previously calibrated with indium at the same heating/cooling rates employed in the analysis. Samples were subjected to two consecutive thermal cycles with the following program: isothermal at $180^{\circ} \mathrm{C}$ for $5 \mathrm{~min}$; heating to $380^{\circ} \mathrm{C}$ at $10^{\circ} \mathrm{C} \mathrm{min}{ }^{-1}$; and cooling to $180{ }^{\circ} \mathrm{C}$ at $10{ }^{\circ} \mathrm{C} \mathrm{min}{ }^{-1}$. The first melting event provided the enthalpy of the crystals formed during the cooling after sintering $\left(\Delta \mathrm{H}^{1}{ }_{\text {melt }}\right)$, while the second melting event is relative to the crystals formed during the cooling in the DSC $\left(\Delta \mathrm{H}^{2}{ }_{\text {melt }}\right)$. Melting enthalpies were determined by integration of the endothermic peaks between the limits $\mathrm{T}_{\text {melt,onset }}=200{ }^{\circ} \mathrm{C}$ and $\mathrm{T}_{\text {melt,endset }}=375^{\circ} \mathrm{C}$ and were used to estimate the degree of crystallinity, since melting enthalpy data of $100 \%$ crystalline PTFE $\left(\Delta \mathrm{H}^{100 \%}{ }_{\text {melt }}\right)$ available in literature are controversial.

\subsection{Scanning Electron Microscopy - SEM}

The occurrence of warts on the surface of some selected samples was observed by SEM, using a Philips model XL 30 microscope operated at a low accelerating voltage of $5 \mathrm{kV}$. Samples were deposited on double-sided carbon tape supported on an aluminum stub, coated with a silver conductive paint and then sputter coated with gold prior to the analysis. 
a)
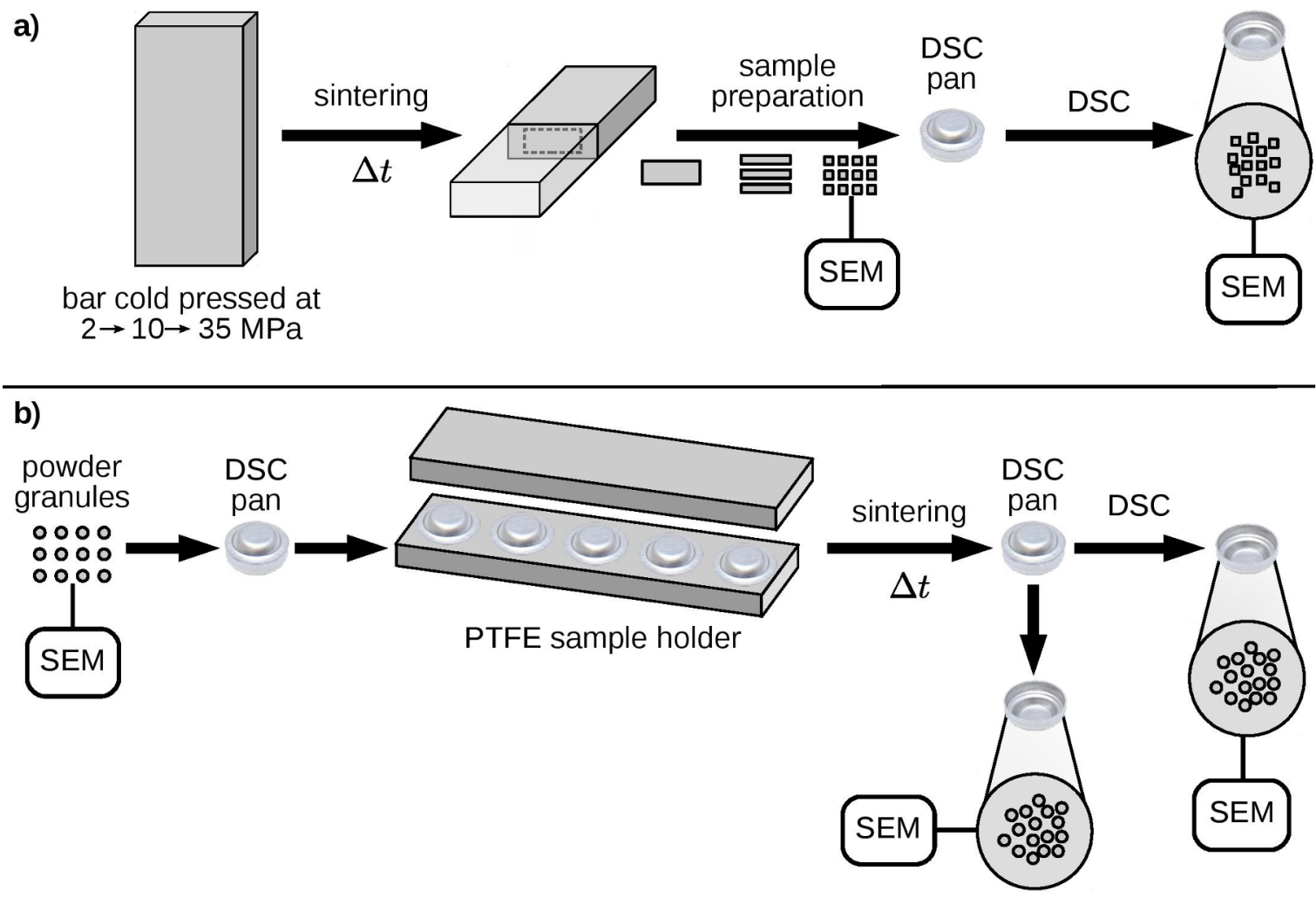

Figure 1. Schematics showing procedures involving DSC and SEM analyses. a) samples composed of small pieces extracted from the core of isostatically cold pressed (CP) and sintered bars. DSC was performed immediately after sintering, while SEM was performed before and after the DSC analysis; b) as-received (non-pressed but sintered) powder granules (PG). DSC was performed immediately after sintering and SEM was performed before sintering and before and after the DSC analysis.

a)

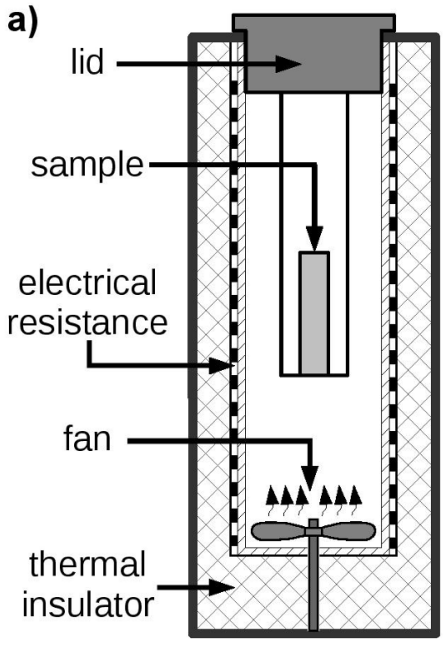

b)

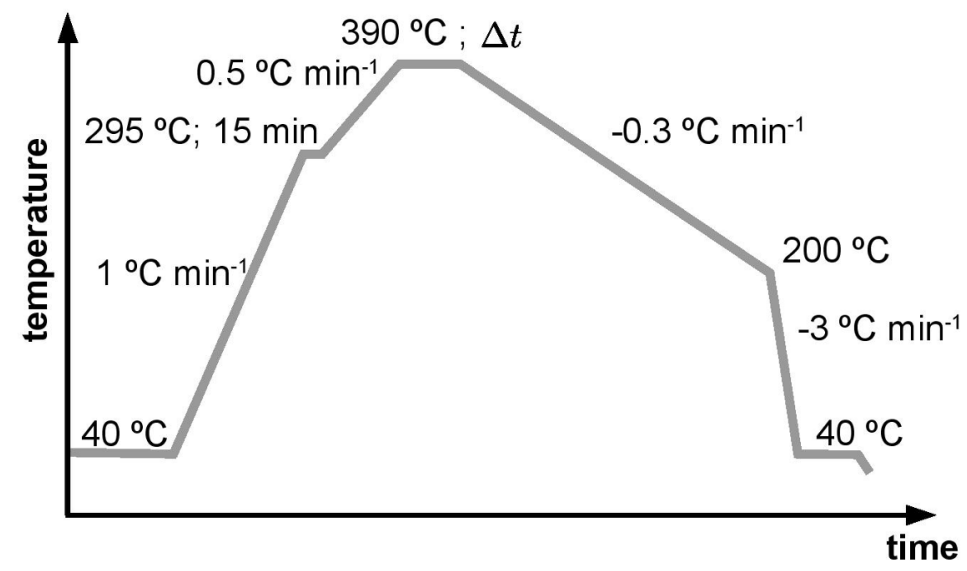

Figure 2. a) Scheme of the oven used for the sintering of the PTFE samples and b) heat treatment program

\section{Results and Discussion}

Figure 3 shows typical DSC thermograms of the powder granules (PG) and cold pressed (CP) samples, which were previously sintered in an oven for $8,000 \mathrm{~min}$. Both samples show single melting and crystallization events in the same temperature ranges but with different enthalpies. As will be shown later, during sintering, and in some instances also during the DSC scan, the PG samples undergo both bulk and superficial (in the form of warts) crystallization, while the CP samples undergo mainly bulk crystallization. 


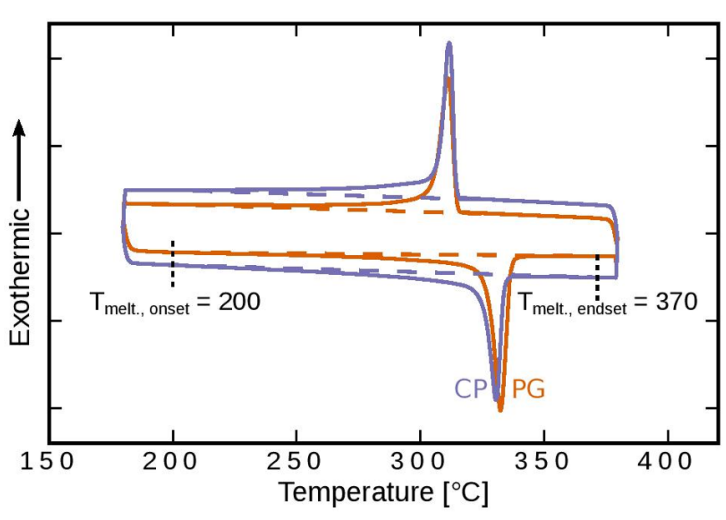

Figure 3. Typical DSC thermograms of cold pressed (CP) and powder granule (PG) samples previously sintered at $390{ }^{\circ} \mathrm{C}$ for $8000 \mathrm{~min}$, with details of the melting and crystallization events and the baselines (dashed lines) used in the integration of the peaks

Therefore, the wart crystallization cannot be distinguished from the bulk crystallization and thus cannot be identified in the DSC analysis. This emphasizes the importance of developing a specific DSC procedure in order to determine and quantify the occurrence of these two crystallization phenomena. Moreover, the procedure should allow the accurate determination of the degree of crystallinity of PTFE parts heat-treated using the typical industrial sintering process, this being the aim of this study.

The melting enthalpies recorded by DSC for PG and $\mathrm{CP}$ samples are shown in Figure 4. The data in Figure 4a were collected during the first heating step in the DSC and relate to the melting enthalpy $\left(\Delta \mathrm{H}^{1}{ }_{\text {mell }}\right)$ of the crystals formed during cooling after the sintering performed at different time intervals, while Figure $4 \mathrm{~b}$ shows the melting enthalpies $\left(\Delta \mathrm{H}_{\text {melt }}^{2}\right)$ of analogous samples that were further cooled and re-heated (labeled as second heating) in the DSC.

$\Delta \mathrm{H}^{1}{ }_{\text {melt }}$ (Figure $4 \mathrm{a}$ ) of both $\mathrm{PG}$ and $\mathrm{CP}$ samples increases abruptly up to $\Delta t \approx 1,000 \mathrm{~min}$. For longer sintering times, that is, $1,000 \mathrm{~min}<\Delta \mathrm{t}<8,000 \mathrm{~min}$, the $\Delta \mathrm{H}^{1}{ }_{\text {melt }}$ of $\mathrm{PG}$ samples tends to level off but there is a slight increase up to $\Delta t=8,000$ min reaching $51 \mathrm{~J} \mathrm{~g}^{-1}$, whereas the $\Delta \mathrm{H}^{1}{ }_{\text {melt }}$ of the $\mathrm{CP}$ samples decreases continuously reaching $42 \mathrm{~J} \mathrm{~g}^{-1}(\approx 18 \%$ lesser$)$ at $\Delta \mathrm{t}=8,000 \mathrm{~min}$. This shows that the sample source, that is, PG or CP, plays a key role in the post-sintering PTFE degree of crystallinity. The dependence of $\Delta \mathrm{H}^{1}{ }_{\text {melt }}$ on the sintering time can be attributed to an interplay of three main factors: i) chain scission due to thermal degradation, which favors the PTFE crystallization resulting in higher melting enthalpy values ${ }^{27}$; ii) disappearance of a remaining "mother phase", which serves as a nucleus for PTFE crystallization and thus leads to an increase in the melting enthalpy ${ }^{22}$; and iii) the formation of crystalline structures called warts on the free surfaces, which increases the resulting melting enthalpy ${ }^{25,26,28}$. For both samples, the abrupt increase in enthalpy up to $\Delta t=$ $1,000 \mathrm{~min}$ is mainly attributed to chain scission due to the thermal degradation of PTFE during sintering, which appears to prevail over the another two factors for short sintering times $^{22}$. Moreover, evidence of the chain scission can be

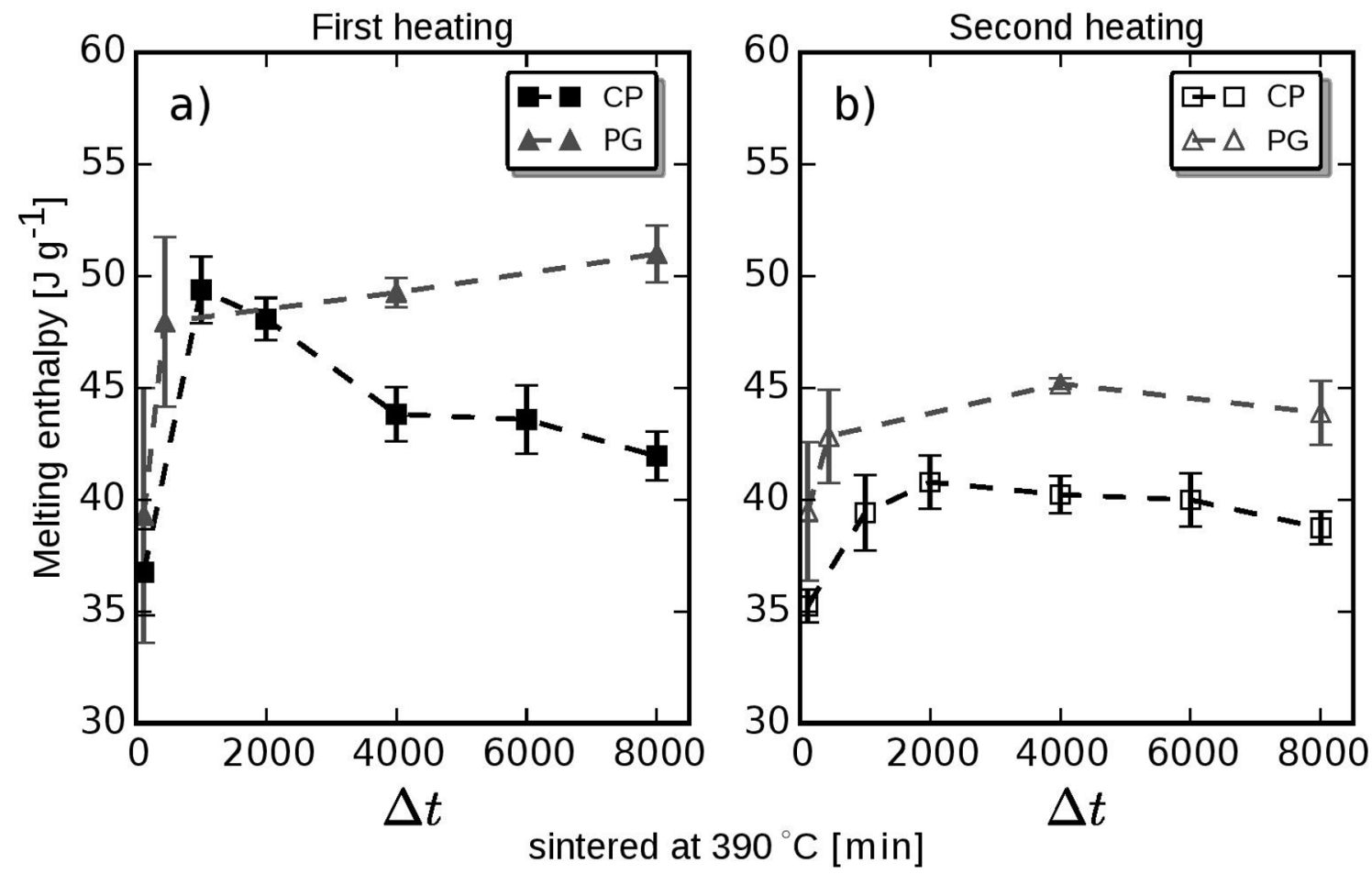

Figure 4. Melting enthalpy values $\Delta \mathrm{H}^{1}{ }_{\text {melt }}$ and $\Delta \mathrm{H}^{2}$ melt measured during the first (a) and second (b) heating steps, respectively, for CP and PG samples previously sintered at $390^{\circ} \mathrm{C}$ with different time intervals $(\Delta \mathrm{t})$. Dashed lines are included for visual guidance. 
noted in the nonstandard experiment carried out by Canto and co-workers ${ }^{3}$. The nonlinearity observed in the degree of crystallinity as a logarithmic function of the cooling rate can be attributed to the sum of the chain scission and the decrease in the cooling rates during the cycles, since both effects favor the crystallization. For the CP samples the decrease in $\Delta \mathrm{H}^{1}{ }_{\text {melt }}$ and thus in the degree of crystallinity thereafter, that is, at 1,000 $\mathrm{min}<\Delta \mathrm{t}<8,000 \mathrm{~min}$, is mainly attributed to the gradual disappearance of a remaining "mother phase". The presence of the "mother phase" is assigned to an additional crystallization peak that appears in the range of 340 to $350^{\circ} \mathrm{C}$ for samples sintered up to $\Delta \mathrm{t}=1,000 \mathrm{~min}^{22}$. This "mother phase" acts as a nucleus, which grows during the cooling and further nucleates the post-sintering crystallization of PTFE, which in turn occurs in the range of 310 to $320^{\circ} \mathrm{C}$, as shown in Figure 3. As this "mother phase" also appears in the PG samples, the increase in enthalpy observed at 1,000 $\min <\Delta \mathrm{t}<8,000 \mathrm{~min}$ for this sample must be a consequence of another phenomenon, which has a greater influence than the first two. This is associated with the formation of crystalline structures called warts ${ }^{25,26,28}$ on the free surfaces of PG samples. In comparison, CP samples have virtually no free surfaces for the formation of warts during sintering, since they are located in the core of dense bars.

The $\Delta \mathrm{H}^{2}{ }_{\text {melt }}$ (Figure $4 \mathrm{~b}$ ) values for both samples (PG and $\mathrm{CP})$ are lower than the corresponding $\Delta \mathrm{H}^{1}{ }_{\text {melt }}$ values, which is ascribed to the difference between the cooling rates applied in the oven $\left(0.3^{\circ} \mathrm{C} \mathrm{min}^{-1}\right)$ and in the DSC $\left(10^{\circ} \mathrm{C} \mathrm{min}^{-1}\right)$. The $\Delta \mathrm{H}^{1}{ }_{\text {melt }}$ of both samples increases suddenly and then tends to level off at $\Delta \mathrm{t}>1,000 \mathrm{~min}$. Clearly, the PG samples show higher $\Delta \mathrm{H}^{1}{ }_{\text {melt }}$ values at a given sintering time as compared to the CP sample, which can be ascribed, as will be shown later, to the higher number of warts formed on the former. This occurs because the PG samples have larger free surfaces, owing to the porosity inside the granules (since they were not previously cold pressed) as well as on the external surface, whereas the free surfaces of CP samples are only external.

The difference between the $\Delta \mathrm{H}^{1}{ }_{\text {melt }}$ and $\Delta \mathrm{H}^{2}{ }_{\text {melt }}$ values for the $\mathrm{CP}$ and $\mathrm{PG}$ samples sintered for given time intervals $(\Delta t)$ motivated the SEM study on the formation of warts. Asreceived PTFE powder granules and some selected samples taken after sintering, along with the corresponding samples subjected additionally to the DSC analysis, were investigated.

Figures 5 shows typical SEM micrographs of the PG (Figures $5 \mathrm{c}-\mathrm{f}$ ) and CP (Figures $5 \mathrm{~g}-\mathrm{j}$ ) samples taken immediately after sintering at $\Delta \mathrm{t}=120$ and $8,000 \mathrm{~min}$. Asreceived PG samples (Figures $5 \mathrm{a}-\mathrm{b}$ ) were also analyzed for comparison. The PG samples have warts on their surfaces after sintering for any time interval, which are characterized by an aspherical shape and a size of approximately $3 \mu \mathrm{m}$. In contrast, the $\mathrm{CP}$ samples did not show the presence of warts, whether they were sintered or not. This corroborates our previous assumption that after sintering warts are formed only on the PG samples, which have large free surfaces owing
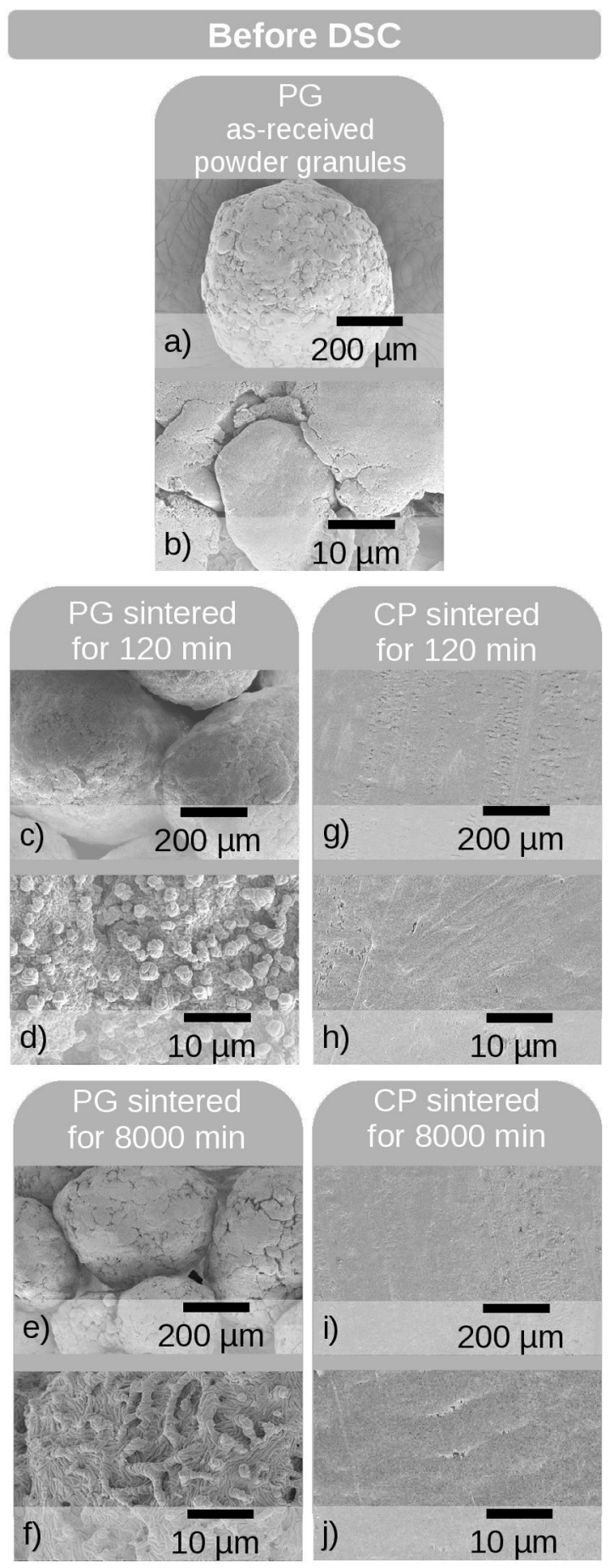

Figure 5. Typical SEM micrographs of PG and CP samples before being subjected to DSC analysis: (a-b) non-pressed but sintered PG samples; (c-f) sintered PG samples; (g-j) cold pressed (CP); and sintered samples

to the porosity inside the granules as well as on the external surfaces. Moreover, for these samples the formation of warts tends to increase with an increase in the sintering time from 120 to $8,000 \mathrm{~min}$, resulting in a network structure probably 
formed by the coalescence of the warts. The formation of a higher number of highly crystalline warts with an increase in the sintering time corroborates the slightly ascending $\Delta \mathrm{H}^{1}{ }_{\text {melt }}$ values for the PG samples, as shown in Figure 4a.

SEM was also applied to the PG and CP samples that were sintered at $390^{\circ} \mathrm{C}$ for $120 \mathrm{~min}$ and further subjected to DSC analysis (Figure 6). Both the PG and CP samples have the presence of warts on their surfaces. This demonstrates that even if a sample did not previously contain warts (as in the case of sintered CP samples), they are formed during the first cooling step in the DSC. This explains why the behavior of the $\Delta \mathrm{H}^{2}$ melt values for the CP samples differs from that of the $\Delta \mathrm{H}^{1}{ }_{\text {melt }}$ values (Figure $4 \mathrm{~b}$ ). Accordingly, the PG samples for which the warts were formed in an earlier step are expected to have a greater number of them after the DSC analysis. This corroborates our previous explanation regarding the $\Delta \mathrm{H}_{\text {melt }}^{2}$ values for the PG and CP samples.

Figure 7 shows the SEM images for the PG and CP samples that were sintered at $390^{\circ} \mathrm{C}$ for the longest time interval, $\Delta \mathrm{t}=8,000 \mathrm{~min}$, and then subjected to further DSC analysis. These samples present a greater number of warts with smaller size as compared to the corresponding

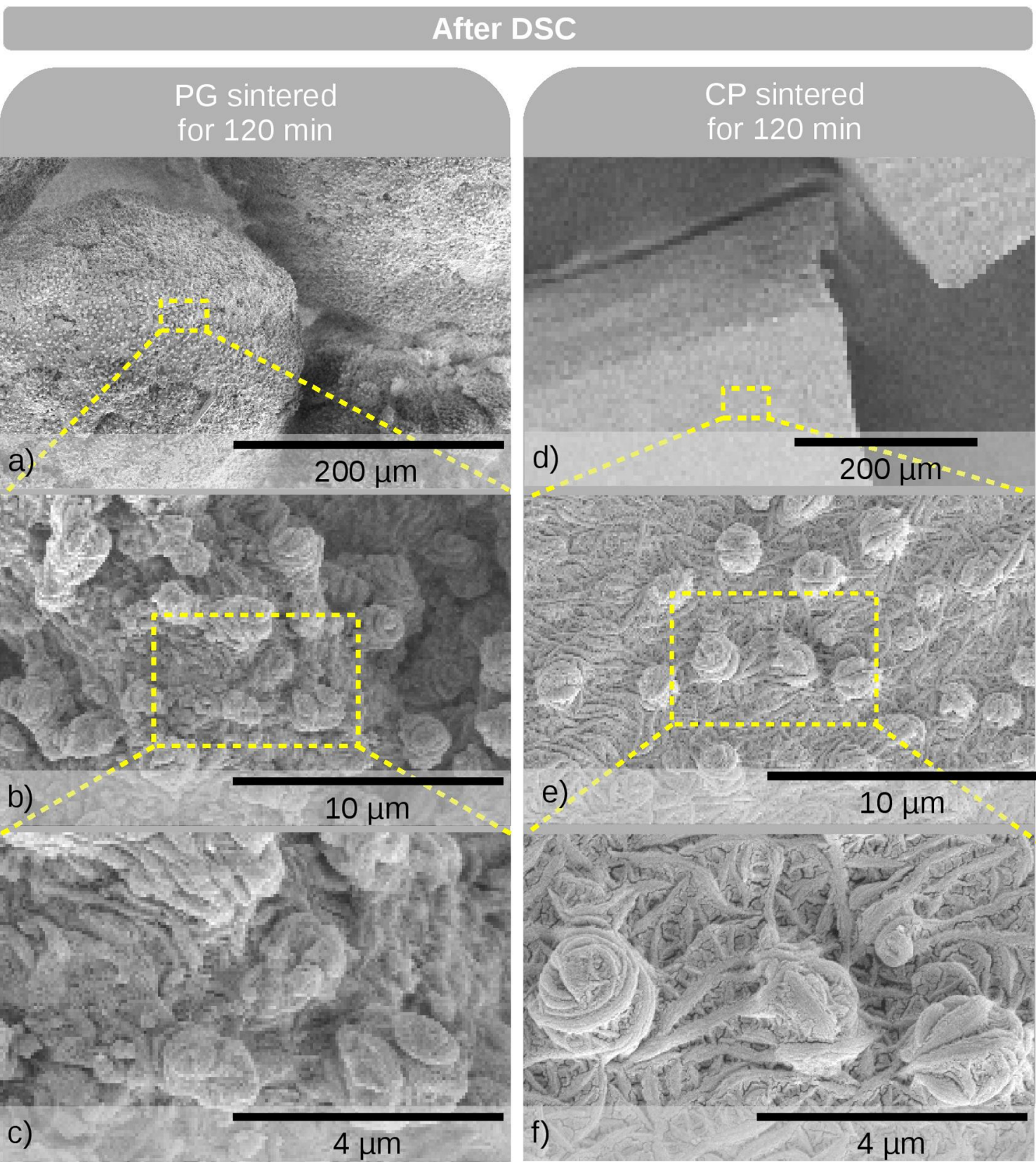

Figure 6. Typical SEM micrographs of PG (a-c) and CP (d-f) samples sintered for 120 min after being subjected to DSC analysis 


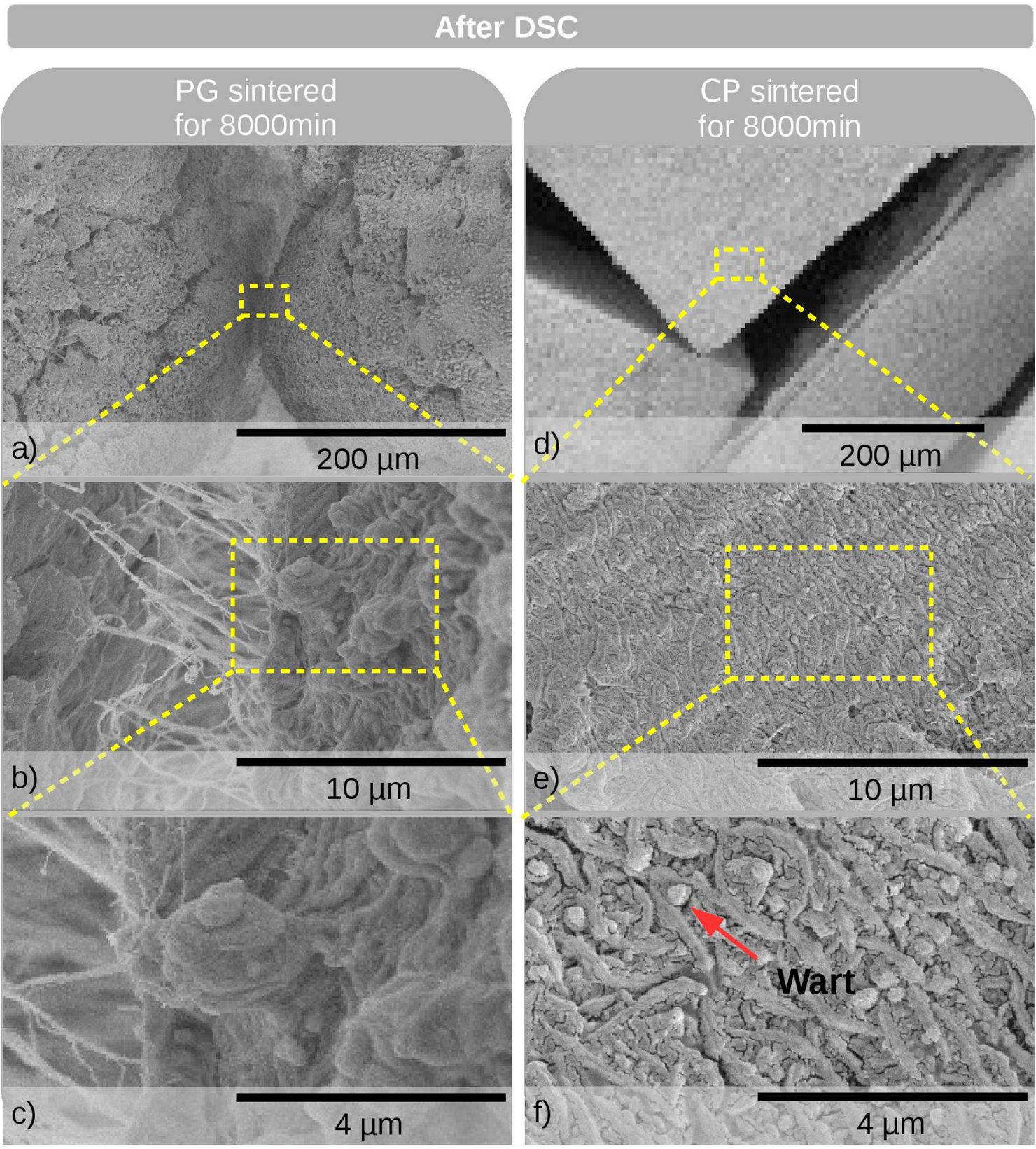

Figure 7. Typical SEM micrographs of PG (a-c) and CP (d-f) samples sintered for 8,000 min and then subjected to further DSC analysis

samples that were sintered for a short time interval, $\Delta \mathrm{t}=$ 120 min (Figure 6).

A reduction in the average size of the warts was observed for the PG samples analyzed via DSC (Figures 6 and 7) with respect to the samples immediately after sintering (Figure 5). This difference can be attributed to the faster cooling rates in DSC analysis $\left(10^{\circ} \mathrm{C} \mathrm{min}^{-1}\right)$ compared with the oven (3 ${ }^{\circ} \mathrm{C} \mathrm{min}^{-1}$ ). This indicates that not only the sintering time (as observed by Glaris and co-workers ${ }^{25}$ ) but also the cooling rate affects the formation of warts. This can be observed in the case of the PG samples sintered at 8,000 min, where the network of warts (Figure $5 \mathrm{f}$ ) is not formed during the cooling in the DSC (Figure 7 a-c). In these samples, a larger number of small warts, that did not coalesce, was observed.

\section{Conclusions}

DSC analysis was performed on PTFE samples in the form of powder granules (PG) subjected to thermal treatment analogous to sintering in an oven as well as on samples 
taken from the core of isostatically cold pressed (CP) parts subjected to the same sintering program. The differences in the melting enthalpy measured during the first heating step in the DSC indicated that sintering affects the crystallization of samples with greater or lesser free surface areas, that is, PG and CP, respectively, in different ways. SEM analysis performed on these samples showed that this difference is caused by the formation of crystalline surface structures called warts on the PG samples, which have large surfaceto-volume ratios. These wart-like structures do not form within the core of isostatically cold pressed dense parts (CP) subjected to analogous sintering, but are formed on the surfaces of samples extracted from such specimens and further subjected to thermal cycling in DSC. Since the surfaces of industrial parts are generally removed during the finish machining operation, on estimating the degree of crystallinity of industrial parts the samples should be free of warts. However, with regard to crystallization and melting events, the crystalline structures (warts) formed on the surface cannot be distinguished from bulk crystals using DSC analysis, since both occur within the same temperature intervals. Therefore, the determination of the degree of crystallinity via a typical DSC routine may result in erroneous results. Based on these observations, we were motivated to develop a DSC procedure for the accurate determination of the degree of crystallinity of cold pressed and sintered industrial parts. For this analysis, samples must be extracted from the core of dense (well-pressed) parts previously sintered in an oven. The use of powder granules and/or sintering by DSC is strongly discouraged as this may result in misleading values. Under the recommended conditions of analysis, the melting enthalpy measured during the first heating step of the DSC is representative of the melting of crystalline structures formed in the whole part as a function of the sintering conditions (temperature, time interval and cooling rate). In the case of other procedures, the PTFE degree of crystallinity could be overestimated by the formation of warts on the surface of the sample.

\section{Acknowledgments}

The authors would like to thank CNPq (the National Council of Technological and Scientific Development process numbers 476215/2013-7 and 130970/2014-0) and FAPESP (São Paulo Research Foundation - process numbers 2010/20925-0, 2012/10319-1, 2013/00256-5 and 2012/253748 ) for the partial financial support of this research.

\section{References}

1. Bonnet JF. Polymères Fluorés. no. AM 3 390. Saint Dennis: Techniques de l'Ingénieur; 2004.

2. Ebnesajjad S. Fluoroplastics Volume 1: Non-Melt Processible Fluoroplastics. $1^{\text {st }}$ ed. Norwich: William Andrew Publishing; 2000.
3. Canto RB, Schmitt N, de Carvalho J, Billardon R. Experimental identification of the deformation mechanisms during sintering of cold compacted polytetrafluoroethylene powders. Polymer Engineering \& Science. 2011;51(11):2220-2235. DOI: 10.1002/ pen.21994

4. Strabelli PG, Sciuti VF, Montilha FS, Canto LB, Canto RB. Effects of sintering variables on the microstructure of isostatically pressed PTFE parts. Polimeros. 2014;24(5):612-619. DOI: 10.1590/0104-1428.1660

5. Mantuano TRA, Gomes AS. Efeito das Condições do Processo de Moldagem e Sinterização para o Politetrafluoroetileno (PTFE) e Polietileno de Ultra Alto Peso Molecular (UHMWPE). Polímeros. 1994;4(1):15-21.

6. Rae PJ, Brown EN. The properties of poly (tetrafluoroethylene) (PTFE) in tension. Polymer. 2005;46(19):8128-8140.

7. Bassett DC, Davitt R. On crystallization phenomena in polytetrafluoroethylene. Polymer. 1974;15(11):721-728.

8. Ashby MF, Johnson K. Materials and Design: The Art and Science of Material Selection in Product Design. Oxford: ButterworthHeinemann; 2013.

9. Rae PJ, Dattelbaum DM. The properties of poly(tetrafluoroethylene) (PTFE) in compression. Polymer. 2004;45(22):7615-7625.

10. Dusunceli N, Colak OU. Modelling effects of degree of crystallinity on mechanical behavior of semicrystalline polymers. International Journal of Plasticity. 2008;24(7):1224-1242.

11. Brown EN, Dattelbaum DM. The role of crystalline phase on fracture and microstructure evolution of polytetrafluoroethylene (PTFE). Polymer. 2005;46(9):3056-3068. DOI: 10.1016/j. polymer.2005.01.061.

12. Brown EN, Dattelbaum DM, Brown DW, Rae PJ, Clausen B. A new strain path to inducing phase transitions in semi-crystalline polymers. Polymer. 2007;48(9):2531-2536.

13. Brown EN, Rae PJ, Orler EB, Gray GT III, Dattelbaum DM. The effect of crystallinity on the fracture of polytetrafluoroethylene (PTFE). Materials Science and Engineering: C. 2006;26(8):13381343.

14. Brown EN, Rae PJ, Liu C. Mixed-mode-I/II fracture of polytetrafluoroethylene. Materials Science and Engineering: A. 2007;468-470:253-258.

15. Sun H, Cooke RS, Bates WD, Wynne KJ. Supercritical $\mathrm{CO}_{2}$ processing and annealing of polytetrafluoroethylene (PTFE) and modified PTFE for enhancement of crystallinity and creep resistance. Polymer. 2005;46(20):8872-8882.

16. Canto RB. Theoretical and experimental study of the compaction and sintering processes of polytetrafluoroethylene (PTFE). [Ph.D. thesis]. São Carlos: São Paulo State University - USP / Cachan: École Normale Supérieure de Cachan; 2007.

17. Frédy C, Canto RB, Schmitt N, Roux S, Billardon R. Modelling of the mechanical behaviour of two pure PTFE powders during their compaction at room temperature. AIP Conference Proceedings. 2013;1542(1):1246-1249.

18. Andena L, Rink M, Polastri F. Simulation of PTFE sintering: Thermal stresses and deformation behavior. Polymer Engineering \& Science. 2004;44(7):1368-1378. 
19. Cochez AC, Canto RB, Canto LB, Schmitt N, Billardon R. A crystallization kinetics model for polytetrafluoroethylene (PTFE) based on two coupled KJMA models. In: $27^{\text {th }}$ Annual Meeting Polymer Processing Society; 2011 May 11; Marrakech, Morocco.

20. Sparnacci K, Antonioli D, Deregibus S, Laus M, Poggio T, Kapeliouchko V, et al. PTFE-Based Core-Soft Shell Nanospheres and Soft Matrix Nanocomposites. Macromolecules. 2009;42(10):3518-3524.

21. Laus M, Sparnacci K, Antonioli D, Deregibus S, Kapeliouchko V, Palamone G, et al. On the multiple crystallization behavior of PTFE in PMMA/PTFE nanocomposites from core-shell nanoparticles. Journal of Polymer Science Part B: Polymer Physics. 2010;48(5):548-554.

22. Strabelli PG. Effects of sintering variables on the microstructure and mechanical properties of isostatically pressed PTFE parts. [Master's dissertation]. São Carlos: Federal University of São Carlos; 2014.

23. Ganguly R, Lesser AJ. Mechanism and kinetics of ultra-high molecular weight polytetrafluoroethylene sintering. Journal of Applied Polymer Science. 2014;131(21).
24. Lau SF, Suzuki H, Wunderlich B. The thermodynamic properties of polytetrafluoroethylene. Journal of Polymer Science Part B: Polymer Physics. 1984;22(3):379-405.

25. Glaris P, Coulon JF, Dorget M, Poncin-Epaillard F. Thermal annealing as a new simple method for PTFE texturing. Polymer. 2013;54(21):5858-5864.

26. Gamboni OO, Riul C, Billardon R, Bose Filho WW, Schmitt N, Canto RB. On the formation of defects induced by air trapping during cold pressing of PTFE powder. Polymer. 2016;82:75-86. DOI: $10.1016 /$ j.polymer.2015.11.014

27. Suwa T, Seguchi T, Takehisa M, Machi S. Effect of molecular weight on the crystalline structure of polytetrafluoroethylene as-polymerized. Journal of Polymer Science Part B: Polymer Physics. 1975;13(11):2183-2194.

28. Jiang C, Hou W, Wang Q, Wang T. Facile fabrication of superhydrophobic polytetrafluoroethylene surface by cold pressing and sintering. Applied Surface Science. 2011;257(11):48214825. DOI: $10.1016 /$ j.apsusc.2010.12.088 